\title{
ANATOMIA DO CAULE DE CORDYLINE SPECTABILIS KUNTH \& BOUCHÉ (LAXMANNIACEAE) ${ }^{1}$
}

\author{
JOSÉNEWTONCARDOSO MARCHIORI ${ }^{2}$
}

\section{RESUMO}

O caule de Cordyline spectabilis Kunth \& Bouché, única espécie de Laxmanniaceae da flora sul-brasileira, é anatomicamente descrito e ilustrado com fotomicrografias, com base em material coletado no Rio Grande do Sul.

Palavras-chave: Cordyline spectabilis, Laxmanniaceae, anatomia do caule.

\section{SUMMARY}

[Stem anatomy of Cordyline spectabilis Kunth \& Bouché (Laxmanniaceae)].

The stem anatomy of Cordyline spectabilis Kunth \& Bouché, the only Laxmanniaceae species in southern brazilian flora, is described and illustrated with photomicrographs, based on material from Rio Grande do Sul state, Brazil

Key words: Cordyline spectabilis, Laxmanniaceae, stem anatomy.

\section{INTRODUÇÃO}

Com cerca de 10 espécies, distribuídas pelas regiões tropicais do mundo, o gênero Cordyline Comm. foi incluído em diferentes famílias botânicas na literatura especializada das últimas décadas, salientando-se: Liliaceae (Dimitri, 1978), Agavaceae (Cronquist, 1981; Reitz et al., 1983), Asteliaceae (Dahlgren et al., 1985), Ruscaceae (Souza \& Lorenzi, 2005) e Lomandraceae (Conran, 1998). Sobre este ponto, Sobral et al. (2006) destacam que o nome Laxmanniaceae, criado em 1901, tem primazia sobre Lomandraceae (de 1911), de acordo com as regras de nomenclatura botânica, motivo pelo qual é atualmente reconhecido como válido, inclusive por APG (1998).

Único representante da família na flora brasileira, Cordyline spectabilis Kunth \& Bouché figura, por vezes, na literatura como Cordyline

\footnotetext{
Recebido em 10-11-2008 e aceito para publicação em 15-12-2008.

2 Engenheiro Florestal, Dr., bolsista de Produtividade em Pesquisa do CNPq, Professor Titular do Departamento de Ciências Florestais, Universidade Federal de Santa Maria (RS).balduinia@mail.ufsm.br
}

dracaenoides Kunth (Dimitri, 1978; Reitz et al., 1983, Brack et al., 1985), binômio reduzido à sinonímia por Pirani \& Cordeiro (2002). Conhecido popularmente como guaraíva (Souza \& Lorenzi, 2005), varaná (Dimitri (1978), tuvarana, palma-de-são-joão, capim-de-anta, uvarana, varana ou varaneira (Reitz et al., 1983), a espécie apresenta caule delgado e cilíndrico de 1-6 $\mathrm{m}$ de altura, marcado por anéis resultantes da deiscência de folhas que, dispostas apenas na extremidade do caule e ramos, são linearlanceoladas (40-80 cm de comprimento), alternas e coriáceas. As flores, pequenas (5-7 mm), azuladas, actinomorfas, trímeras e de perianto bisseriado, reúnem-se em amplas panículas terminais. O fruto, do tipo baga, mede cerca de 5 mm de diâmetro, contendo sementes de cor escura. Cordyline spectabilis é nativa da América do Sul tropical, incluindo Misiones (Argentina) e Rio Grande do Sul; neste Estado, habita em clareiras e na orla das florestas do Alto Uruguai e das matas com Araucária.

Desconhecido até o momento, o estudo anatômico do caule de Cordyline spectabilis constitui o objetivo do presente trabalho. Para Dracaena, gênero afim, Record \& Hess (1943) 


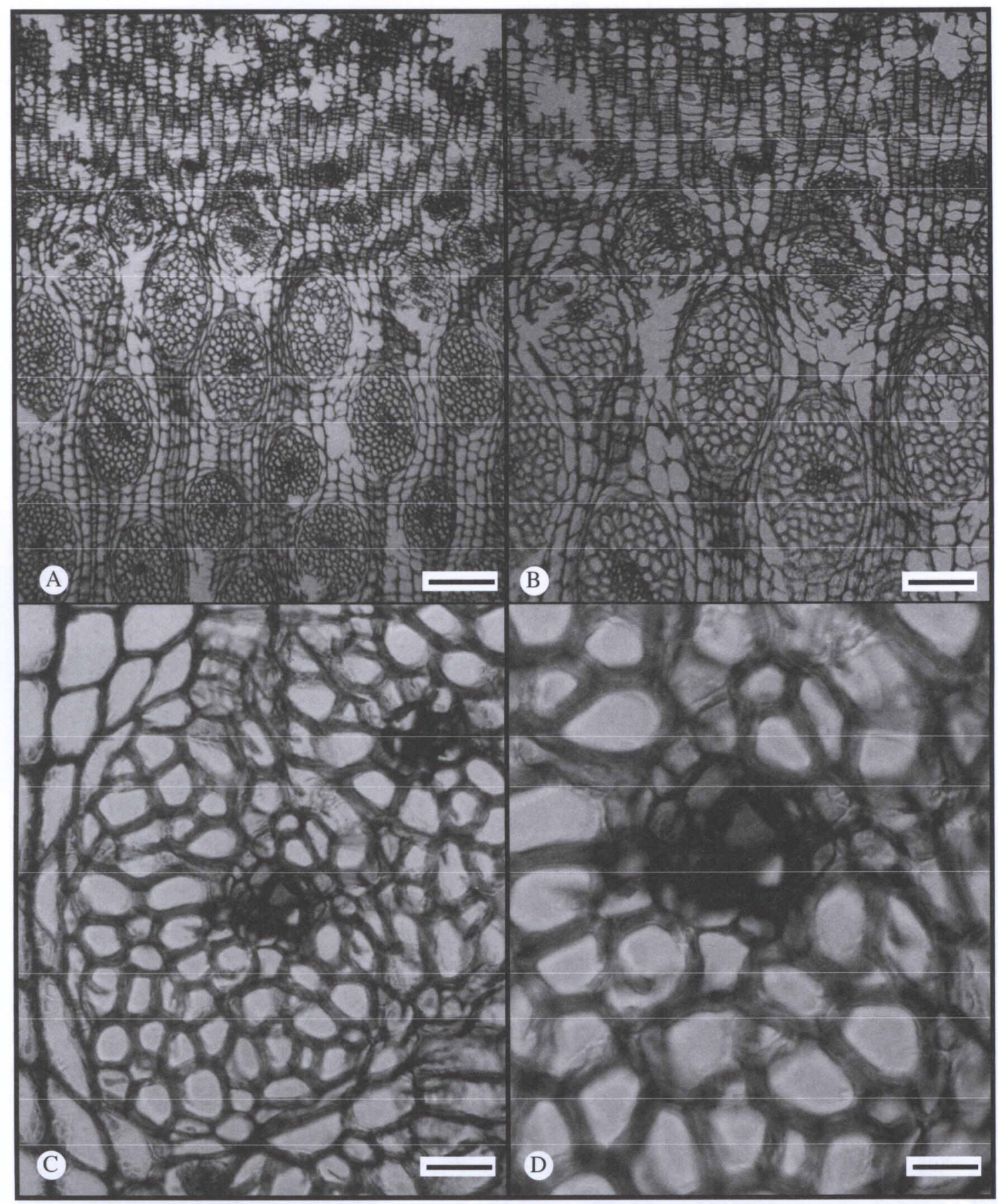

FIGURA 1 - Fotomicrografias do caule de Cordyline spectabilis, em corte transversal. A,B - Aspecto geral, destacando o meristema secundário de engrossamento e feixes vasculares anfixilemáticos (escalas: $A=250 \mu \mathrm{m} ; \mathrm{B}=160 \mu \mathrm{m})$. C - Dois feixes vasculares, com tecido fundamental à esquerda $($ escala $=80 \mu \mathrm{m})$. D - Floema no centro de um feixe, rodeado de traqueídeos (escala $=32 \mu \mathrm{m})$. 
referem, entre outros caracteres: anéis de crescimento ausentes; feixes xilemáticos muito numerosos, de seção elíptica a alongados radialmente; células parenquimáticas de paredes finas a moderadamente espessas; cordões fibrovasculares compostos de traqueídeos com lúmens grandes, paredes espessas e pontoações areoladas circulares conspícuas, com aberturas lenticulares; e floema disposto no centro dos feixes, com freqüentes extensões unisseriadas ligando ao tecido matriz parenquimático.

\section{MATERIAL E MÉTODOS}

O material analisado, incluindo segmento do caule e material botânico fértil, foi coletado no município de Nonoai, noroeste do Rio Grande do Sul, e anexado à Xiloteca e Herbário Departamento de Ciências Florestais da Universidade Federal de Santa Maria, sob o número 2816
(Marchiori, J.N.C., n. 436; 18-8-1986). Logo após a coleta, o caule foi acondicionado em vidro com álcool $70 \%$, com vistas à fixação.

$\mathrm{Da}$ amostra de caule foram preparados bloquinhos, orientados para a obtenção de cortes transversais e longitudinais. Os bloquinhos foram amolecidos por fervura em água, submetidos à inclusão em polietilenoglicol $1000 \mathrm{e}$ seccionados em micrótomo de deslizamento, regulado para a obtenção de cortes anatômicos com espessura nominal de $20 \mu \mathrm{m}$. Os cortes obtidos sofreram coloração com acridina-vermelha, crisoidina e azul-de-astra (Dujardin, 1964) e montados em lâminas permanentes com Entellan.

As fotomicrografias (Figuras 1 e 2) foram tomadas em aparelho Carl Zeiss, no Laboratório de Anatomia da Madeira da Universidade Federal do Paraná.

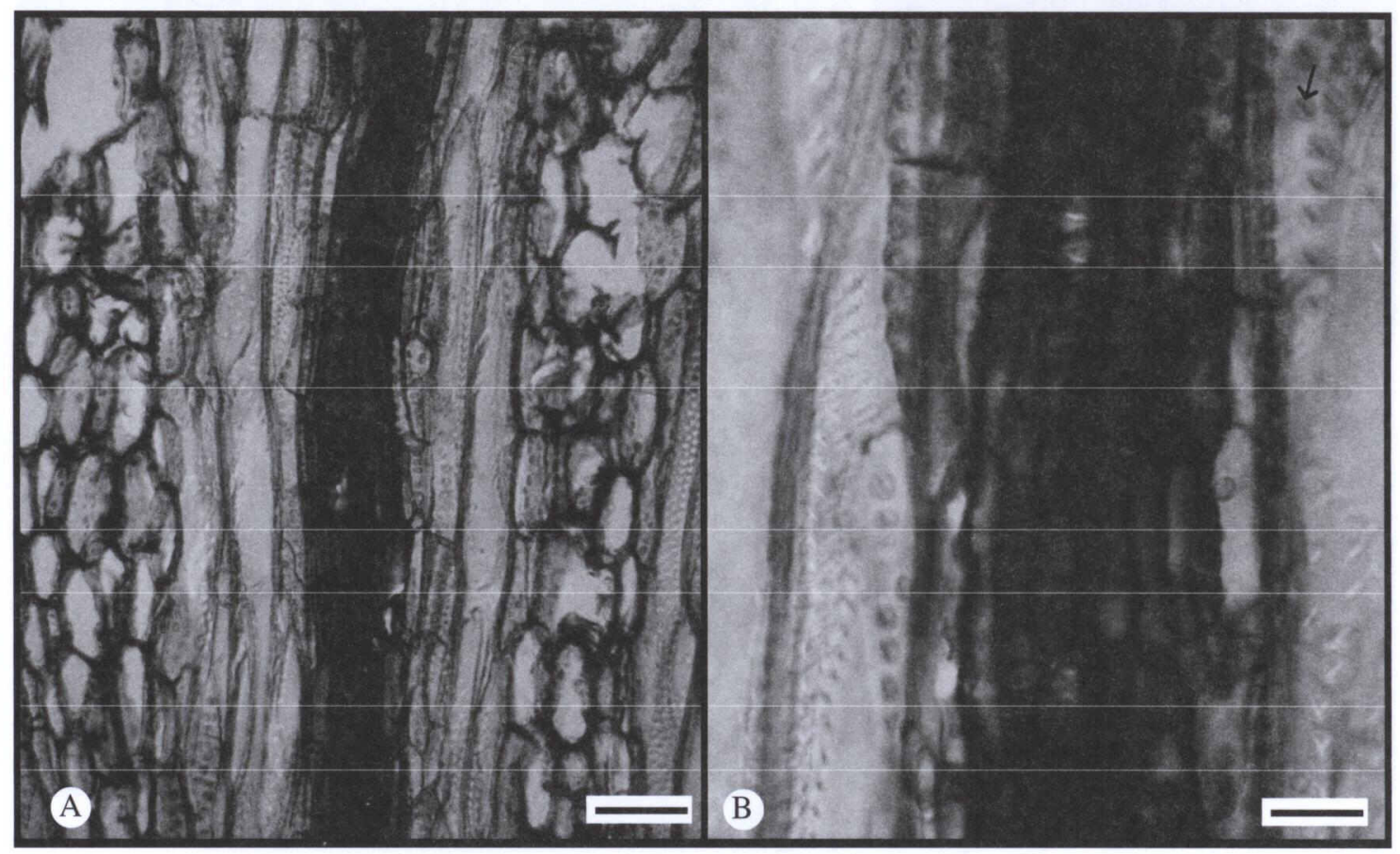

FIGURA 2 - Dois aspectos de feixes vasculares anfixilemáticos em corte longitudinal, destacando o floema, ao centro, rodeado por traqueídeos com pontoações areoladas (seta). Escalas: $\mathrm{A}=80 \mu \mathrm{m} ; \mathrm{B}=32 \mu \mathrm{m}$. 


\section{DESCRIÇÃO DO CAULE}

Anéis de crescimento, ausentes. Estrutura caulinar provida de meristema secundário de engrossamento (Figura 1A,B), responsável pela acréscimo de novos feixes líbero-lenhosos ao cilindro vascular.

Cilindro central com tecido fundamental de natureza parenquimática, composto de células dispostas em alinhamento radial (Figura 1A,B), indicando sua origem a partir do referido meristema secundário.

Os feixes vasculares, anfixilemáticos, compreendem um anel externo de traqueídeos e núcleo central floemático (Figura 1C,D). Os traqueídeos, de paredes espessas e lúmens relativamente grandes, apresentam pontoações areoladas em arranjo oposto até alterno, com cerca de $5 \mu \mathrm{m}$ de diâmetro e aberturas lenticulares cruzadas em x (Figura 2A,B).

\section{ANÁLISE DA ESTRUTURA ANATÔMICA}

Os caracteres anatômicos observados no caule de Cordyline spectabilis Kunth \& Bouché correspondem, em linhas gerais, ao referido por Record \& Hess (1943) para o gênero Dracaena: anéis de crescimento indistintos; feixes xilemáticos numerosos, compostos de traqueídeos com pontoações circulares e floema central; e tecido fundamental de natureza parenquimática. Independentemente da família botânica em que a espécie em estudo for inserida, trata-se de um grupo relativamente homogêneo de Angiospermas Monocotiledôneas, distinto pela presença de feixes vasculares anfixilemáticos, em vez de elementos vasculares.
REFERÊNCIASBIBLIOGRÁFICAS

APG (The Angiosperm Phylogeny Group). An ordinal classification for the flowering plants. Annals of the Missouri Botanical Garden, n. 85, p. 531$555,1998$.

BRACK, P., BUENO, R. M., FALKENBERG, D. B., PAIVA, M. R. C., SOBRAL, M., STEHMANN, J. R. Levantamento florístico do Parque Estadual do Turvo, Tenente Portela, Rio Grande do Sul, Brasil. Roessléria, Porto Alegre, v. 7, n. 1, p. 6994, 1985.

CONRAN, J. G. Lomandraceae. In: KUBITZKI, K. (ed.). The families and genera offlowering plants. Berlin: Springer, 1998. v. 3, p. 354-365.

CRONQUIST, A. An integrated system of classification of flowering plants. New York: Columbia University Press, 1981. 1262 p.

DAHLGREN, R. M. T., CLIFFORD, H. T., YEO, P. F. The families of Monocotyledons. Berlin: Springer Verlag, $1985.520 \mathrm{p}$.

DIMITRI, M. J. Enciclopedia argentina de Agricultura y Jardineria. Buenos Aires: ACME, 1978. v. 1. 651 p.

DUJARDIN, E. P. Eine neue Holz-zellulosenfaerbung. Mikrokosmos, n. 53, p. 94, 1964.

PIRANI, J. R., CORDEIRO, I. Agavaceae. In: WANDERLEY, M. G. L., SHEPHERD, G., GIULIETTI, A. M. (orgs.). Flora fanerogâmica do Estado de São Paulo. São Paulo: Hucitec, 2002. v. 2. p. 5-8.

RECORD, S.J., HESS, R. W. Timbers of the New World. New Haven: Yale University Press, 1943. 640 p.

REITZ, R., KLEIN, R. M., REIS, A. Projeto Madeira do Rio Grande do Sul. Sellowia, Itajaí, n. 34-35, p. $1-525,1983$.

SOBRAL, M., BRACK, P., LAROCCA, J., RODRIGUES, R. S. Flora arbórea e arborescente do Rio Grande do Sul, Brasil. São Carlos: RiMA: Novo Ambiente, 2006.350 p.

SOUZA, V.C.,LORENZI, H. Botânica sistemática. Guia ilustrado para identificação das famílias de Angiospermas da flora brasileira, baseado em APG II. Nova Odessa: Instituto Plantarum, 2005. 640 p. 